\title{
Association of genes of lipid metabolism with measures of subclinical cardiovascular disease in the Diabetes Heart Study
}

\author{
K P Burdon, C D Langefeld, S R Beck, L E Wagenknecht, J J Carr, B I Freedman, D Herrington, \\ D W Bowden
}

\begin{abstract}
Background: Dyslipidaemia is a well known risk factor for cardiovascular disease (CVD). Lipid metabolism is affected by a range of genes and proteins. This study investigated whether some of these genes are associated with measures of subclinical CVD.

Methods: Polymorphisms of paraoxonase 1 and 2, cholesteryl ester transfer protein, hepatic lipase, and lipoprotein lipase were tested for associations with measures of subclinical CVD including carotid intima-media thickness measured by B-mode ultrasound and carotid and coronary arterial calcification measured by computed tomography. Analysis was performed in 620 European American participants in the Diabetes Heart Study, $83 \%$ of whom had type 2 diabetes mellitus. Associations of genotypes with subclinical CVD were tested by computing a series of generalised estimating equations.

Results: The Q192R variant of paraoxonase 1 and rs285 of lipoprotein lipase were associated with carotid artery calcium ( $p$ values $=0.002$ and 0.005 , respectively). Paraoxonase 2 S311C was associated with coronary artery calcium ( $p$ value $=0.037$ )

Conclusions: There is evidence for modest, but significant, association of multiple single nucleotide polymorphisms in lipid genes with measures of subclinical CVD.
\end{abstract}

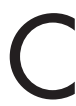
ardiovascular disease (CVD) susceptibility is widely believed to be the product of lifestyle and environment interacting with genetic factors. ${ }^{12}$ In addition to traits such as smoking, body mass index (BMI), hypertension, and gender, major risk factors for CVD include increased triglycerides and low density lipoprotein (LDL) and decreased high density lipoprotein (HDL). Levels of triglycerides, LDL, and HDL and their metabolism are affected by a broad range of genes and their protein products. For example, paraoxonases 1 and 2 (PON1 and PON2), ${ }^{3}$ cholesteryl ester transfer protein (CETP), ${ }^{4}$ hepatic lipase (HL), ${ }^{5}$ and lipoprotein lipase $(\mathrm{LPL})^{6}$ are all contributors to the metabolism of lipoproteins. They have previously been the subject of several studies with the goal of identifying genes associated with various metabolic and clinical measures of CVD in several populations with varied results.

In this study, we have investigated common variants of PON1, PON2, CETP, HL, and LPL for association with measures of subclinical CVD in European American individuals from the Diabetes Heart Study (DHS). The DHS is a single centre, family based study, designed to locate and identify genes contributing to CVD in families enriched for type 2 diabetes mellitus (T2DM). ${ }^{78} \mathrm{~T} 2 \mathrm{DM}$ is an independent risk factor for CVD and the investigation of diabetic individuals enriches for CVD, providing an improved distribution for measures of subclinical disease over general population samples with little disease. In addition to conventional risk factors, subclinical CVD has been quantitatively assessed in the DHS through measurement of intimamedia thickness (IMT) of the common carotid artery, and coronary artery calcification (CAC) and carotid artery calcification (CarAC). The DHS has shown that both IMT and CAC have a significant heritable component ${ }^{78}$ and they independently have been shown to correlate with atherosclerosis and clinical CVD, ${ }^{9-12}$ making these useful noninvasive surrogate measures.

Several studies have tested for associations between genetic variants in a variety of genes and IMT in both diabetic and non-diabetic populations, ${ }^{13}$ although the results have been highly variable. Genetic determinants of CAC have been less intensively studied due to the novelty of the phenotype, but evidence exists that several genes may contribute to this useful marker of atherosclerosis. ${ }^{14}$ In the DHS we have the capability to assess genetic association of both IMT and CAC in a set of families enriched for T2DM and atherosclerosis. This makes it a powerful resource for the mapping or identification of genes contributing to CVD.

\section{METHODS}

The recruitment and phenotyping of DHS participants have been previously described. ${ }^{78}$ Briefly, siblings concordant for T2DM with no renal insufficiency were recruited along with any available unaffected siblings. All protocols were approved by the institutional review board of Wake Forest University School of Medicine and all participants gave informed consent. Participant examinations were conducted in the General Clinical Research Center of the Wake Forest University Baptist Medical Center and included interviews for medical history and health behaviours, anthropometric measures, resting blood pressure, fasting blood sampling, and spot urine collection. Laboratory assays included urine albumin and creatinine, total cholesterol, HDL, triglycerides, HbAlc, fasting glucose, and blood chemistries. IMT of the common carotid artery was measured by high resolution Bmode ultrasonography with a $7.5 \mathrm{MHz}$ transducer and a Biosound Esaote (AU5) ultrasound machine as previously described. ${ }^{7}$ CAC and CarAC were measured using fast gated helical CT scanners and calcium scores calculated as

Abbreviations: $\mathrm{BMl}$, body mass index; CAC, coronary artery calcification; CarAC, carotid artery calcification; CETP, cholesteryl ester transfer protein; CVD, cardiovascular disease; DHS, Diabetes Heart Study; IMT, intima-media thickness; HL, hepatic lipase; LPL, lipoprotein lipase; PON1, paraoxonase 1; PON2, paraoxonase 2; SNP, single nucleotide polymorphism; T2DM, type 2 diabetes mellitus 
described previously. ${ }^{8}$ In addition to the European American participants the DHS includes an African American component; however, the power to detect genetic association in this ethnic group is limited due to the relatively small numbers of participants (15\% of the total cohort) and analyses of this sample are not presented here.

\section{Genetic analysis}

Total genomic DNA was purified from whole blood samples obtained from subjects using the PUREGENE DNA Isolation Kit (Gentra, Minneapolis, MN). DNA was quantitated using standardised fluorometric readings on a Hoefer DyNA Quant 200 fluorometer (Hoefer Pharmacia Biotech, San Francisco, CA). Each sample was diluted to a final concentration of $5 \mathrm{ng} / \mu \mathrm{l}$.

Single nucleotide polymorphisms (SNPs) genotyped were: L55M and Q192R of PONl; S311C of PONI2; rs289714, I405V, and R45IQ of CETP; C-480T of HL; and rs285 and rs320 of LPL. SNP rs289714 is referred to in previous literature as intron $9+29 \mathrm{~A} \rightarrow \mathrm{G} .{ }^{15}$ The variants of the LPL gene rs285 and rs320 are referred to in the literature as PvuII and HindIII, respectively. C-629A of CETP was considered for genotyping, however, this variant was not suitable for genotyping on the high throughput Sequenom platform used in this study. In addition, this variant is also in strong linkage disequilibrium with R451Q. SNP genotypes were determined using a MassARRAY SNP genotyping system (Sequenom, San Diego, CA) as previously described. ${ }^{16}$ This genotyping system uses single base extension reactions to create allele specific products that are separated and automatically scored in a MALDI-TOF mass spectrometer. Primers for PCR amplification and extension reactions are designed using SpectroDESIGNER assay design software (Sequenom).

\section{Statistical analyses}

Allele and genotype frequencies were calculated from unrelated probands and tested for departure from HardyWeinberg proportions using a $\chi^{2}$ test. To test for an association among the polymorphisms of each individual SNP and each trait, a series of generalised estimating equations $\left(\mathrm{GEE}^{17}{ }^{17}\right)$ was computed. Familial correlation was accounted for by using a sandwich estimator of the variance and exchangeable correlation. Four tests of association were performed for each SNP and trait combination. Specifically, the two degree of freedom overall test of genotypic association and, if significant, the three individual contrasts defined by the a priori genetic models (that is, dominant, additive, recessive) were computed. The dominant model tests for differences between the combined $1 / 2$ and 2/2 genotypes $v$ the $1 / 1$ genotype (that is, presence $v$ absence of allele 2 ). The additive model tests for a cumulative effect of allele 2 . The recessive model tests for differences between genotype $2 / 2 \mathrm{v}$ $1 / 1$ and $1 / 2$ (that is, two copies of allele 2 ). Caution should be employed when examining tests of association when the number of individuals within the least common category is small (for example, recessive model with a rare variant). Tests were computed making adjustment for covariates age, gender, diabetes status, smoking status, and lipid lowering medication use. IMT, CAC, and CarAC values were log transformed to best approximate the distributional assumptions of the test and to minimise heterogeneity of variance. A $\mathrm{p}$ value of $<0.05$ was considered significant.

\section{RESULTS}

DNA from 620 European American individuals in 230 families comprising 656 sibling pairs was genotyped. Included in the sample was one single affected individual, 132 pedigrees with one affected sibling pair, 43 trios, 42 pedigrees with four siblings, four pedigrees with five siblings, seven pedigrees with six siblings, and one complex pedigree. Parents were available for only three pedigrees. Of the 620 subjects, 512 have diagnosed T2DM. The clinical characteristics of all European American subjects and the diabetic subset are given in table 1 . The genotype frequencies of all SNPs genotyped are presented in table 2, calculated in unrelated individuals. All variants are consistent with HardyWeinberg proportions. All frequencies are similar to previously reported values in European American populations.

\section{Association analysis}

The statistical significances for the overall genotypic associations are presented in table 2. Significant associations were detected for PON1 Q192R with CarAC, PON2 S311C with CAC, and LPL rs285 also with CarAC, with the $p$ values ranging from 0.037 to 0.002 . Analyses were also conducted in diabetic participants alone with results similar to those with all participants (data not shown). Genotypic means for each trait (untransformed) where a significant association was detected are presented in table 3. The RR genotype of PON 1 Q192R was associated with greater carotid calcium, and a smaller percentage of homozygous individuals had a score of 0 , suggesting that it is correlated with an increased risk of CVD. Similarly, allele 2 of LPL rs 285 was associated with decreased CarAC, and a greater percentage of homozygous individuals had 0 CarAC, indicating a decreased risk of CVD. Allele 2 of PON2 S311C was associated with lower coronary calcium scores also correlating with a decreased risk of CVD, however, the number of individuals with 0 CAC was too small to see a trend.

An inheritance model based analysis may be more powerful than the overall test of association and may provide additional information on the most likely mode of inheritance. However, this study was not statistically powered to distinguish between these models. The inheritance model based analyses were therefore only considered when the overall test of association was significant. The associations of

Table 1 Clinical characteristics of participants

\begin{tabular}{|c|c|c|}
\hline & $\begin{array}{l}\text { Mean } \pm \text { SD } \\
\text { or } \%(n)\end{array}$ & Median (range) \\
\hline Age (years) & $61.6 \pm 9.6$ & $61.9(33-83)$ \\
\hline Gender ( $\%$ female) & $55.6(345)$ & - \\
\hline Duration of diabetes (years) & $10.7 \pm 7.7$ & $9.0(1-59)$ \\
\hline BMI $\left(\mathrm{kg} / \mathrm{m}^{2}\right)$ & $31.7 \pm 6.8$ & $30.6(16-59)$ \\
\hline \multicolumn{3}{|l|}{ Smoking } \\
\hline Current (\%) & $19.8(122)$ & - \\
\hline Past (\%) & $40.1(247)$ & - \\
\hline Never (\%) & $40.1(247)$ & - \\
\hline Lipid lowering medication (\%) & $37.3(230)$ & - \\
\hline \multicolumn{3}{|c|}{ Laboratory } \\
\hline Total cholesterol (mg/dl) & $189.6 \pm 43.2$ & $185.5(74-391)$ \\
\hline HDL cholesterol (mg/dl) & $43.2 \pm 12.8$ & $41.0(18-90)$ \\
\hline LDL cholesterol (mg/dl) & $106.1 \pm 32.6$ & $103.0(14-200)$ \\
\hline Triglycerides $(\mathrm{mg} / \mathrm{dl})$ & $209.3 \pm 136.8$ & $179.0(38-1310)$ \\
\hline Glycated haemoglobin (\%) & $7.5 \pm 1.9$ & $7.1(3.5-18.3)$ \\
\hline Fasting glucose (mg/dl) & $141.5 \pm 59.0$ & $127(46-463)$ \\
\hline Albumin/creatinine ratio & $111.7 \pm 525.6$ & $10.6(0.8-9449)$ \\
\hline \multicolumn{3}{|l|}{ Prevalent CVD conditions } \\
\hline Hypertension (\%) & $78.2(485)$ & - \\
\hline Angina (\%) & $19.5(110)$ & - \\
\hline Myocardial infarction (\%) & $20.3(124)$ & - \\
\hline Stroke (\%) & $9.7(59)$ & - \\
\hline Endarterectomy (\%) & $2.3(14)$ & - \\
\hline $\begin{array}{l}\text { Coronary artery bypass } \\
\text { graft (\%) }\end{array}$ & $14.7(91)$ & - \\
\hline IMT (mm) & $0.683 \pm 0.139$ & $0.661(0.46-1.57)$ \\
\hline Coronary artery calcium score & $1173 \pm 2437$ & $244(0-25420)$ \\
\hline Carotid artery calcium score & $344 \pm 700$ & $71(0-6122)$ \\
\hline
\end{tabular}


Table 2 Allele frequencies in unrelated individuals and $\mathrm{p}$ values for genotypic association, adjusted for age, gender, diabetes status, smoking status, and lipid lowering medication use

\begin{tabular}{|c|c|c|c|c|c|c|c|c|}
\hline \multirow[b]{2}{*}{ Gene } & \multirow[b]{2}{*}{ SNP } & \multicolumn{2}{|c|}{ Allele $1^{*}$} & \multicolumn{2}{|c|}{ Allele $2^{*}$} & \multicolumn{3}{|c|}{$p$ values $(n=620)$} \\
\hline & & \multicolumn{2}{|c|}{ Frequency } & \multicolumn{2}{|c|}{ Frequency } & IMT & CAC & CarAC \\
\hline \multirow[t]{2}{*}{ PONI } & L55M & $T(L)$ & 0.61 & $A(M)$ & 0.39 & 0.806 & 0.596 & 0.611 \\
\hline & Q192R & $A(Q)$ & 0.71 & $G(R)$ & 0.29 & 0.106 & 0.719 & 0.002 \\
\hline PON2 & S311C & $C(S)$ & 0.77 & $\mathrm{G}(\mathrm{C})$ & 0.23 & 0.735 & 0.037 & 0.303 \\
\hline \multirow[t]{3}{*}{ CETP } & rs289714 & A & 0.82 & $G$ & 0.18 & 0.077 & 0.997 & 0.798 \\
\hline & $1405 \mathrm{~V}$ & $G(V)$ & 0.29 & $A(I)$ & 0.71 & 0.497 & 0.469 & 0.347 \\
\hline & R451Q & $G(R)$ & 0.94 & $A(Q)$ & 0.06 & 0.203 & 0.601 & 0.435 \\
\hline $\mathrm{HL}$ & C-480T & C & 0.80 & $T^{\circ}$ & 0.20 & 0.410 & 0.937 & 0.549 \\
\hline \multirow[t]{2}{*}{ LPL } & rs 285 & T & 0.50 & C & 0.50 & 0.441 & 0.292 & 0.005 \\
\hline & rs 320 & $\mathrm{~T}$ & 0.73 & G & 0.27 & 0.374 & 0.427 & 0.820 \\
\hline
\end{tabular}

*Allele 1 and allele 2 are given at the nucleotide level, with the corresponding amino acid allele in parentheses for coding SNPs.

PON1 Q192R and LPL rs285 with CarAC were strongest under a recessive model ( $\mathrm{p}$ values $=0.0004$ and 0.002 , respectively) as was the association of PON2 S311C with CAC ( $p$ values $=0.078)$, although this does not reach statistical significance. These observations are consistent with the differences observed in mean trait values presented in table 3.

\section{DISCUSSION}

The results of this study show that several common variants of genes involved in lipid metabolism are significantly associated with subclinical CVD. Specifically, the paraoxonase genes and LPL are associated with measures of arterial calcification. These genes do not appear to be important determinants of common carotid artery IMT. Although it has been shown to be heritable, ${ }^{8} 18$ and a genome wide scan has been conducted, ${ }^{19}$ very few genes have so far been found to be associated with coronary artery calcium. Among those identified are MMP3, MGP, CCR2, ACE, APOE, E-selectin, EPHX2, and HL, ${ }^{14} 2021$ all of which still require confirmation in independent samples. To this list we now add PON2. Additionally, this is the first report to our knowledge of a genetic association with carotid artery calcium and we present evidence that both PONI and LPL are associated with this phenotype.

The two paraoxonase genes are associated with calcified arterial plaque, PON1 Q192R in the carotid artery and PON2 S311C in the coronary artery. The literature suggests that the $\mathrm{R}$ allele of Q192R has a reduced ability to protect lipids from oxidative modification compared with the Q allele. This has been observed for lipid associated with $\mathrm{LDL}^{22}$ as well as free lipid in atherosclerotic lesions in both the carotid and coronary arteries. ${ }^{23}$ This is consistent with the association of the $\mathrm{R}$ allele with coronary heart disease demonstrated in a meta-analysis of case-control studies ${ }^{24}$ and the increased CAC score in RR homozygotes observed in the current study.
Furthermore, in this study, the G allele of PON2 S311C, coding for cysteine, appears to reduce levels of coronary artery calcium, indicating that it may reduce the risk of CVD. This study adds to the evidence of PON involvement with CVD through investigation of a subclinical quantitative measure of CVD in a diabetic population.

The LPL gene SNP rs285 was also associated with carotid artery calcium in this study. Rare genetic LPL deficiencies are known to cause severe dyslipidaemias. Several coding variants are known and have been investigated in multiple studies. A meta-analysis indicates that these variants are associated with plasma triglyceride, HDL levels, and possibly ischaemic heart disease, with a small effect size. ${ }^{25}$ However, most are rare (minor allele frequencies $<0.05)^{26}$ and therefore in this study we chose to investigate the more common rs285 (PvuII) and rs320 (HindIII) polymorphisms in order to increase the statistical power and improve the chance of detecting a variant making a significant contribution to CVD in European American populations. These intronic SNPs have also been previously associated with coronary artery disease in European Americans ${ }^{27} 28$ and while they are probably not functional SNPs, they are likely to be in linkage disequilibrium with causative variants. Haplotypes of the LPL gene have been associated with both insulin resistance and CAD in Mexican Americans, ${ }^{29}{ }^{30}$ although the associations of individual SNPs were weak. The linkage disequilibrium observed between the two polymorphisms in the current study is low $\left(\mathrm{D}^{\prime}=0.55\right)$ and therefore haplotype analysis with these particular variants is of limited value.

The literature concerning these genes and association with CVD traits is varied and often contradictory. In this case, no association of CETP or HL with CVD was detected despite previous reports that both genes are associated with IMT. ${ }^{15} 31$ This is a common theme in genetic research for common but complex traits and can partly be explained by investigations in different populations and subpopulations and by different

Table 3 Distribution of trait values for all subjects by genotype class for cardiovascular traits significantly associated $(p<0.05)$ with genetic variants

\begin{tabular}{|c|c|c|c|c|c|c|c|c|c|c|c|c|}
\hline \multirow[b]{3}{*}{ Gene } & \multirow[b]{3}{*}{ SNP } & \multirow[b]{3}{*}{ Trait } & \multirow[b]{3}{*}{$P$ value } & \multicolumn{9}{|c|}{ Genotypes } \\
\hline & & & & \multicolumn{3}{|l|}{$\overline{1 / 1}$} & \multicolumn{3}{|l|}{$1 / 2$} & \multicolumn{3}{|l|}{$2 / 2$} \\
\hline & & & & $\mathrm{n}$ & Mean \pm SD & $\% n=0$ & $n$ & Mean \pm SD & $\% n=0$ & $n$ & Mean \pm SD & $\% n=0$ \\
\hline $\begin{array}{l}\text { PON1 } \\
\text { PON2 } \\
\text { LPL }\end{array}$ & $\begin{array}{l}\text { Q192R } \\
\text { S311C } \\
\text { rs285 }\end{array}$ & $\begin{array}{l}\text { CarAC } \\
\text { CAC } \\
\text { CarAC }\end{array}$ & $\begin{array}{l}0.002 \\
0.037 \\
0.005\end{array}$ & $\begin{array}{l}264 \\
281 \\
164\end{array}$ & $\begin{array}{l}348.9 \pm 746.4 \\
1127.0 \pm 1996 \\
326.9 \pm 631.3\end{array}$ & $\begin{array}{r}21.2 \\
4.6 \\
18.9\end{array}$ & $\begin{array}{l}235 \\
162 \\
324\end{array}$ & $\begin{array}{l}331.5 \pm 680.2 \\
1216.0 \pm 2820 \\
375.5 \pm 758.1\end{array}$ & $\begin{array}{r}26.0 \\
7.4 \\
18.5\end{array}$ & $\begin{array}{r}28 \\
25 \\
134\end{array}$ & $\begin{array}{l}496.4 \pm 702.0 \\
851.0 \pm 1331 \\
274.3 \pm 519.6\end{array}$ & $\begin{array}{r}10.7 \\
4.0 \\
26.1\end{array}$ \\
\hline
\end{tabular}

$\% \mathrm{n}=0$ refers to the percentage of individuals by genotype with a calcium score of $0 . C A C$, coronary artery calcification; CarAC, carotid artery calcification; SD, standard deviation. 
methodologies. HL was also found to be associated with coronary calcification in type 1 diabetes patients. ${ }^{21}$ The different etiologies of type 1 and type 2 diabetes may account for this difference. Type I error (false positive results) may also account for some of the differences between studies, particularly in small sample sizes as in the report by Rundek et al describing an association of the HL gene with IMT in only 87 stroke free individuals. ${ }^{31}$ This collection of 620 individuals is one of the larger studies, which should improve power to detect true associations; however, SNP allele frequency combined with the small expected effect size still limits the power and makes stratification of the sample and investigation of complex environmental and genetic interactions uninformative. Corrections for multiple comparisons have not been made. All the SNPs chosen were in candidate genes previously reported as playing a role in CVD and with the exception of the LPL SNPs and CETP rs289714, are potentially functional variants, providing a priori hypotheses for their association with measures of CVD.

There is some chance that the associations detected here are spurious, particularly as the recessive model is most likely and the number of homozygotes for the minor allele of the PON genes is small. In this study only a few variants of each gene were studied. There exists substantially more variation in these genes which may be confounding these results if the marker used is represented on both a risk and a non-risk haplotype. Future work will require in depth investigations of the total genetic variation of each gene as well as subsequent multilocus and haplotype analyses in order to determine those at risk of CVD based on the genetic profile.

These genes all play important roles in lipid metabolism and therefore a contribution of these SNPs to lipid levels could be expected. This predominantly diabetic sample has moderate to severe dyslipidaemia (table 1) and $40 \%$ of patients were taking lipid lowering medications which will inevitably affect lipid levels making an accurate assessment of the genetic contribution difficult. The contribution of these genes to lipid levels may be better assessed in a more representative population sample. It is interesting that no associations were detected with carotid IMT, particularly as PONl appears to be influencing atherosclerosis in the carotid artery. While both IMT and calcification are surrogate measures of CVD, they appear to measure different aspects of the disease, as indicated by the small correlation observed between the traits. ${ }^{32}$

CVD and T2DM are complex diseases with many overlapping risk factors and likely have many interdependencies. This study has identified several polymorphisms correlating with subclinical CVD in T2DM families. Specifically, genetic variation of the PON1, PON2, and LPL genes appears to contribute to arterial calcification in a European American diabetic population, suggesting that the pathways involving these genes may be useful therapeutic targets for individuals carrying risk alleles.

\footnotetext{
Authors' affiliations

K P Burdon, D W Bowden, Center for Human Genomics, Wake Forest University School of Medicine, Winston-Salem, NC, USA

C D Langefeld, S R Beck, L E Wagenknecht, Department of Public Health Sciences, Wake Forest University School of Medicine, Winston-Salem, NC, USA

J J Carr, Department of Radiology, Wake Forest University School of Medicine, Winston-Salem, NC, USA

B I Freedman, D Herrington, Department of Internal Medicine, Wake Forest University School of Medicine, Winston-Salem, NC, USA

This study was supported in part by the General Clinical Research Center of the Wake Forest University School of Medicine grant M01 RR07122, and grant NHLBI RO1 HL67348 awarded to DWB. KPB was supported by an American Diabetes Association Mentor-based Fellowship.
}

Competing interests: none declared

Ethics approval: All protocols were approved by the institutional review board of Wake Forest University School of Medicine and all participants gave informed consent.

Correspondence to: Donald W Bowden, Department of Biochemistry, Wake Forest University School of Medicine, Medical Center Boulevard, Winston-Salem, NC 27157, USA; dbowden@wfubmc.edu

Revised version received 6 January 2005

Accepted for publication 7 January 2005

\section{REFERENCES}

1 Lusis AJ. Atherosclerosis. Nature 2000;407:233-41.

2 Harrap SB, Stebbing M, Hopper JL, Hoang HN, Giles GG. Familial patterns of covariation for cardiovascular risk factors in adults: the Victorian Family Heart Study. Am J Epidemiol 2000;152:704-15.

3 Mackness MI, Arrol S, Abbott C, Durrington PN. Protection of low-density lipoprotein against oxidative modification by high-density lipoprotein associated paraoxonase. Atherosclerosis 1993;104:129-35.

4 Morton RE, Zilversmit DB. Inter-relationship of lipids transferred by the lipidtransfer protein isolated from human lipoprotein-deficient plasma. J Biol Chem 1983:258:11751-7.

5 Jansen H, Verhoeven AJ, Weeks L, Kastelein JJ, Halley DJ, van den Ouweland A, Jukema JW, Seidell JC, Birkenhager JC. Common C-to-T substitution at position -480 of the hepatic lipase promoter associated with a lowered lipase activity in coronary artery disease patients. Arterioscler Thromb Vasc Biol 1997; 17:2837-42.

6 Mulder M, Lombardi P, Jansen H, van Berkel TJ, Frants RR, Havekes LM. Low density lipoprotein receptor internalizes low density and very low density lipoproteins that are bound to heparan sulfate proteoglycans via lipoprotein lipase. J Biol Chem 1993;268:9369-75.

7 Lange LA, Bowden DW, Langefeld CD, Wagenknecht LE, Carr JJ, Rich SS, Riley WA, Freedman BI. Heritability of carotid artery intima-medial thickness in type 2 diabetes. Stroke 2002;33:1876-81.

8 Wagenknecht LE, Bowden DW, Carr JJ, Langefeld CD, Freedman BI, Rich SS. Familial aggregation of coronary artery calcium in families with type 2 diabetes. Diabetes 2001;50:861-6.

9 Bots ML, Hoes AW, Koudstaal PJ, Hofman A, Grobbee DE. Common carotid intima-media thickness and risk of stroke and myocardial infarction: the Rotterdam Study. Circulation 1997;96:1432-7

10 Chambless LE, Heiss G, Folsom AR, Rosamond W, Szklo M, Sharrett AR, Clegg LX. Association of coronary heart disease incidence with carotid arterial wall thickness and major risk factors: the Atherosclerosis Risk in Communities (ARIC) Study, 1987-1993. Am J Epidemiol 1997;146:483-94.

11 Sangiorgi G, Rumberger JA, Severson A, Edwards WD, Gregoire J, Fitzpatrick LA, Schwartz RS. Arterial calcification and not lumen stenosis is highly correlated with atherosclerotic plaque burden in humans: a histologic study of 723 coronary artery segments using nondecalcifying methodology. J Am Coll Cardiol 1998;31:126-33.

12 Budoff MJ, Georgiou D, Brody A, Agatston AS, Kennedy J, Wolfkiel C, Stanford W, Shields P, Lewis RJ, Janowitz WR, Rich S, Brundage BH. Ultrafast computed tomography as a diagnostic modality in the detection of coronary artery disease: a multicenter study. Circulation 1996;93:898-904.

13 Zannad F, Benetos A. Genetics of intima-media thickness. Curr Opin Lipidol 2003; 14:191-200.

14 Doherty TM, Fitzpatrick LA, Shaheen A, Rajavashisth TB, Detrano RC. Genetic determinants of arterial calcification associated with atherosclerosis. Mayo Clin Proc 2004;79:197-210.

15 Kakko S, Tamminen M, Paivansalo M, Kauma H, Rantala AO, Lilja M, Reunanen A, Kesaniemi YA, Savolainen MJ. Variation at the cholesteryl ester transfer protein gene in relation to plasma high density lipoproteins cholesterol levels and carotid intima-media thickness. Eur J Clin Invest 2001;31:593-602.

16 Bensen JT, Langefeld CD, Hawkins GA, Green LE, Mychaleckyi JC, Brewer CS, Kiger DS, Binford SM, Colicigno CJ, Allred DC, Freedman BI, Bowden DW. Nucleotide variation, haplotype structure, and association with end-stage renal disease of the human interleukin-1 gene cluster. Genomics 2003;82:194-217.

17 Zeger SL, Liang KY. Longitudinal data analysis for discrete and continuous outcomes. Biometrics 1986;42:121-30.

18 Peyser PA, Bielak LF, Chu JS, Turner ST, Ellsworth DL, Boerwinkle E, Sheedy PF 2nd. Heritability of coronary artery calcium quantity measured by electron beam computed tomography in asymptomatic adults. Circulation 2002; 106:304-8.

19 Lange LA, Lange EM, Bielak LF, Langefeld CD, Kardia SL, Royston P, Turner ST, Sheedy PF 2nd, Boerwinkle E, Peyser PA. Autosomal genome-wide scan for coronary artery calcification loci in sibships at high risk for hypertension. Arterioscler Thromb Vasc Biol 2002;22:418-23.

20 Fornage $M$, Boerwinkle $E$, Doris PA, Jacobs D, Liu K, Wong ND. Polymorphism of the soluble epoxide hydrolase is associated with coronary artery calcification in African-American subjects: the Coronary Artery Risk Development in Young Adults (CARDIA) study. Circulation 2004; 109:335-9.

21 Hokanson JE, Cheng S, Snell-Bergeon JK, Fijal BA, Grow MA, Hung C, Erlich HA, Ehrlich J, Eckel RH, Rewers M. A common promoter polymorphism in the hepatic lipase gene (LIPC- $480 C>T$ ) is associated with an increase in coronary calcification in type 1 diabetes. Diabetes 2002;51:1208-13. 
22 Mackness B, Mackness MI, Arrol S, Turkie W, Durrington PN. Effect of the human serum paraoxonase 55 and 192 genetic polymorphisms on the protection by high density lipoprotein against low density lipoprotein oxidative modification. FEBS Lett 1998;423:57-60.

23 Aviram M, Hardak E, Vaya J, Mahmood S, Milo S, Hoffman A, Billicke S, Draganov D, Rosenblat M. Human serum paraoxonases (PON1) Q and R selectively decrease lipid peroxides in human coronary and carotid atherosclerotic lesions: PON1 esterase and peroxidase-like activities. Circulation 2000;101:2510-7.

24 Durrington PN, Mackness B, Mackness MI. Paraoxonase and atherosclerosis. Arterioscler Thromb Vasc Biol 2001;21:473-80

25 Wittrup HH, Tybjaerg-Hansen A, Nordestgaard BG. Lipoprotein lipase mutations, plasma lipids and lipoproteins, and risk of ischemic heart disease. A meta-analysis. Circulation 1999.99.2901-7.

26 Spence JD, Ban MR, Hegele RA. Lipoprotein lipase (LPL) gene variation and progression of carotid artery plaque. Stroke 2003;34:1 176-80.

27 Anderson JL, King GJ, Bair TL, Elmer SP, Muhlestein JB, Habashi J, Mixson L, Carlquist JF. Association of lipoprotein lipase gene polymorphisms with coronary artery disease. J Am Coll Cardiol 1999;33:1013-20.
28 Wang XL, McCredie RM, Wilcken DE. Common DNA polymorphisms at the lipoprotein lipase gene. Association with severity of coronary artery disease and diabetes. Circulation 1996;93:1339-45.

29 Goodarzi MO, Guo X, Taylor KD, Quinones MJ, Samayoa C, Yang H, Saad MF, Palotie A, Krauss RM, Hsueh WA, Rotter Jl. Determination and use of haplotypes: ethnic comparison and association of the lipoprotein lipase gene and coronary artery disease in Mexican-Americans. Genet Med gene and coron $2003: 5: 322-7$.

30 Goodarzi MO, Guo X, Taylor KD, Quinones MJ, Saad MF, Yang H, Hsueh WA, Rotter JI. Lipoprotein lipase is a gene for insulin resistance in Mexican Americans. Diabetes 2004:53:214-20.

31 Rundek T, Elkind MS, Pittman J, Boden-Albala B, Martin S, Humphries SE, Juo SH, Sacco RL. Carotid intima-media thickness is associated with allelic variants of stromelysin-1, interleukin-6, and hepatic lipase genes: the Northern Manhattan Prospective Cohort Study. Stroke 2002;33:1420-3.

32 Wagenknecht LE, Langefeld CD, Carr JJ, Riley W, Freedman BI, Moossavi S, Bowden DW. Race-specific relationships between coronary and carotid artery calcification and carotid intimal medial thickness. Stroke 2004;35:e97-9.

\section{Clinical Evidence-Call for contributors}

Clinical Evidence is a regularly updated evidence-based journal available worldwide both as a paper version and on the internet. Clinical Evidence needs to recruit a number of new contributors. Contributors are healthcare professionals or epidemiologists with experience in evidence-based medicine and the ability to write in a concise and structured way.

Areas for which we are currently seeking authors:

- Child health: nocturnal enuresis

- Eye disorders: bacterial conjunctivitis

- Male health: prostate cancer (metastatic)

- Women's health: pre-menstrual syndrome; pyelonephritis in non-pregnant women

However, we are always looking for others, so do not let this list discourage you.

Being a contributor involves:

- Selecting from a validated, screened search (performed by in-house Information Specialists) epidemiologically sound studies for inclusion.

- Documenting your decisions about which studies to include on an inclusion and exclusion form, which we keep on file.

- Writing the text to a highly structured template (about 1500-3000 words), using evidence from the final studies chosen, within 8-10 weeks of receiving the literature search.

- Working with Clinical Evidence editors to ensure that the final text meets epidemiological and style standards.

- Updating the text every six months using any new, sound evidence that becomes available. The Clinical Evidence in-house team will conduct the searches for contributors; your task is simply to filter out high quality studies and incorporate them in the existing text.

- To expand the topic to include a new question about once every 12-18 months.

If you would like to become a contributor for Clinical Evidence or require more information about what this involves please send your contact details and a copy of your CV, clearly stating the clinical area you are interested in, to Klara Brunnhuber (kbrunnhuber@ bmigroup.com).

\section{Call for peer reviewers}

Clinical Evidence also needs to recruit a number of new peer reviewers specifically with an interest in the clinical areas stated above, and also others related to general practice. Peer reviewers are healthcare professionals or epidemiologists with experience in evidence-based medicine. As a peer reviewer you would be asked for your views on the clinical relevance, validity, and accessibility of specific topics within the journal, and their usefulness to the intended audience (international generalists and healthcare professionals, possibly with limited statistical knowledge). Topics are usually 1500-3000 words in length and we would ask you to review between 2-5 topics per year. The peer review process takes place throughout the year, and our turnaround time for each review is ideally 10-14 days.

If you are interested in becoming a peer reviewer for Clinical Evidence, please complete the peer review questionnaire at www.clinicalevidence.com or contact Klara Brunnhuber (kbrunnhuber@bmigroup.com). 